\title{
ANÁLISE AMBIENTAL E SOCIODEMOGRÁFICA DO PÓLO DE JEREMOABO: A MOBILIDADE DO TRABALHO E A MIGRAÇÃO
}

\author{
$\underline{\text { Aryane Sinval Alves }}$; Nacelice Barbosa Freitas ${ }^{2}$
}

1. Bolsista PIBIC/FAPESB, Graduanda de Bacharelado em Geografia, Universidade Estadual de Feira de Santana, email: aryanesalves@ gmail.com

2. Orientadora, Departamento de Ciências Humanas e Filosofia, Universidade Estadual de Feira de Santana, e-mail: nacegeografic@hotmail.com

PALAVRAS-CHAVE: Mobilidade do Trabalho; Migração; Desertificação.

\section{INTRODUÇÃO}

O processo de desertificação em climas áridos e semiáridos também provoca implicações no âmbito social, a migração torna-se uma alternativa para àqueles que convivem nessas áreas climáticas, e especificamente no semiárido brasileiro, observa-se como forma de resistirem à situação socioambiental e política.

A mobilidade do trabalho é de suma importância para explicar a dinâmica sociodemográfica, pois, os movimentos migratórios podem está relacionado às "desigualdades regionais advindas do espaço transformado, do arranjo espacial das atividades produtivas." (SINGER, 1973 apud SOARES, 2004, p. 104). Sendo assim, é possível discutir a questão socioestrutural da organização do espaço resultantes das relações capitalistas.

Diante do exposto, o texto tem o objetivo de analisar a relação entre migração e mobilidade do trabalho através dos dados sociodemográficos dos municípios que integram o Pólo de Jeremoabo para explicar as consequências do processo de desertificação. Especificamente avalia-se a relação entre mobilidade do trabalho e migração a partir de dados sociodemográficos observando como está se relaciona com o a desertificação. Finalmente, traça-se o mapeamento das desigualdades socioespaciais a partir dos dados de mobilidade do trabalho, identificando os municípios mais vulneráveis aos efeitos da desertificação.

\section{MATERIAIS E MÉTODOS}

No Estado da Bahia, o Pólo de Jeremoabo foi caracterizado por esta pesquisa como o mais propenso aos efeitos desse processo, podendo-se afirmar que os municípios que integram o pólo - Canudos, Uauá, Macururé, Rodelas, Chorrochó, Paulo Afonso, Glória, Santa Brígida, Pedro Alexandre, Coronel João Sá, Novo Trunfo, Antas e Jeremoabo - encontram-se em vulnerabilidade. (FIGURA 1)

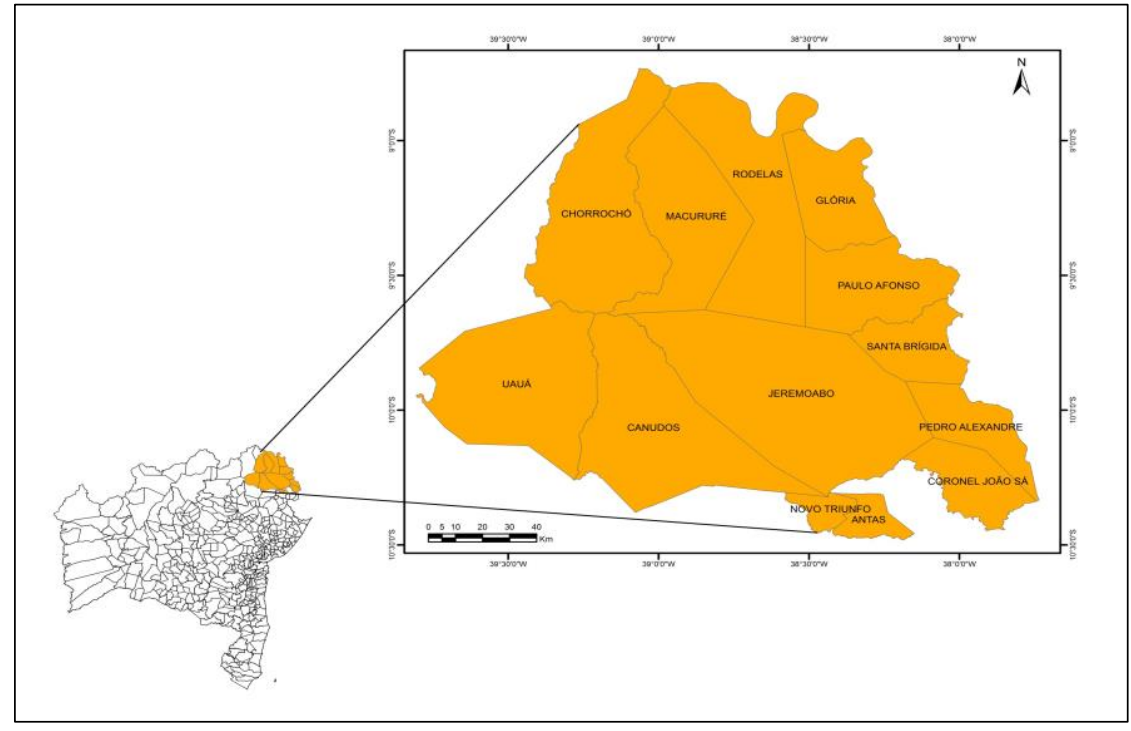


Figura 1:Pólo de Jeremoabo: localização da área dos municípios da Bahia. Fonte: Censos Demográficos do Instituto Brasileiro de Geografia e Estatística (IBGE-2010)

Para a realização do estudo foi necessário numa primeira etapa, o levantamento bibliográfico buscando as definições dos conceitos de Migração, especificamente por Lewis (1954), Neto (1997) e Mobilidade do Trabalho por Salim (1992), Gaudemar (1977). Em seguida, coletaram-se informações estatísticas sobre deslocamento populacional para trabalhar em 2010 em órgãos que pesquisam indicadores sociodemográficos, especificamente, o Instituto Brasileiro de Geografia e Estatística (IBGE). Posteriormente, foi produzido um banco de dados contendo número que indicam ocupações exercidas identificando-se as direções das migrações em busca de trabalho, após, construiu-se tabelas organizando os números através de gráficos, chegando à sistematização das categorias migratórias e os setores profissionais do trabalho, teve-se uma visão geral sobre a evolução dos números.

Ao final, conclui-se com a espacialização dos dados estatísticos mapeando a vulnerabilidade socioespacial no Pólo de Jeremoabo observando as consequências da mobilidade do trabalho, assim como a susceptibilidade á desertificação coma utilização de software de geoprocessamento ArcVierw e ArcMap e a finalização auxiliado pelo CorelDraw.

\section{RESULTADOS}

Os conceitos de migração e mobilidade do trabalho podem ser definidos em diversas perspectivas, resultam do deslocamento populacional, desse modo, é possível confrontar as discussões. Segundo Lewis (1954) a migração é vista como um processo positivo, pois será possível o fluxo de excedente da população migrar para espaços onde atraem mão de obra, pois ocorre o deslocamento populacional de um setor profissional para outro. Para Salim (1992), com a mobilidade do trabalho a migração deixa de ser reflexo do espaço modificado para atuar como elemento transformador operando em dimensão espacial, possibilita-se, então identificar as formas concretas de mobilidade do trabalho. Gaudemar (1979) vai analisar a mobilidade do trabalho como fenômeno que causa o deslocamento espacial, setorial e profissional do trabalhador, com a finalidade do capital explorar sua força de trabalho e acumular o excedente econômico. Neto (1997, p. 19) ressalta que "a migração não é, pois, mero mecanismo de redistribuição espacial das populações, adaptando-se as solicitações do sistema socioeconômico." Sendo assim, irá interferir na direção dos fluxos de pessoas, pois é determinado pela lógica do capital ao produzir e controlar a oferta de força de trabalho.

Analisando os dados referentes ao deslocamento populacional dos municípios do Pólo de Jeremoabo em 2010, foi possível identificar que eles estão relacionados á questão do trabalho, configurando assim as categorias migratórias em temporária e pendular. Na migração temporária observou-se que os setores de agricultura, construção civil, indústria, serviço doméstico e outras atividades de prestação de serviço são os que mais atraem força de trabalho, provocando significativa a saída de pessoas do município de onde moram para trabalhar. A migração pendular, porém, identificam-se os setores de comércio, trabalho informal, construção civil, agricultura, e indústria como os principais responsáveis pela atração de mão de obra. Ao comparar os dados entre as duas categorias, pode-se afirmar que a migração temporária influencia mais no deslocamento populacional, e, ambas as migrações ocorrem de forma mais efetiva nos municípios de Paulo Afonso, Jeremoabo, Chorrochó, Novo Triunfo, Glória e Antas.

As desigualdades socioespaciais no Pólo de Jeremoabo foram identificadas a partir das ocupações populacionais dos migrantes que estavam relacionadas em ter um emprego, ou mais de um emprego. 
Os dados sobre o deslocamento populacional para as pessoas que trabalham em mais de um município demonstram que migraram 381 pessoas em Paulo Afonso, 209 pessoas em Jeremoabo, 191 em Antas, 59 pessoas em Canudos, 34 pessoas em Uauá, 22 pessoas em Coronel João Sá, 20 pessoas em Macururé, 12 pessoas em Chorrochó e Santa Brígida, 8 pessoas em Glória, 5 pessoas em Rodelas, já para Pedro Alexandre e Novo Triunfo não ocorreram emigração. Ou seja, obteve a média semanal de aproximadamente, 20 a 100 migrantes.

Os números referentes às pessoas que trabalham fora do município indicam que em Antas foi de 174 pessoas migrando, em Canudos 245 pessoas, Chorrochó 284 pessoas, Coronel João Sá 145 pessoas, Glória 1.005 pessoas, Jeremoabo 654 pessoas, Macururé 146 pessoas, Novo Triunfo 63 pessoas, Paulo Afonso 4.674 pessoas, Pedro Alexandre 107 pessoas, Rodelas 31 pessoas, Santa Brígida 456 pessoas e Uauá 368 pessoas. Ou seja, tiveram valores médios semanal de aproximadamente, 100 a 500 migrantes.

Pode-se observar que, a busca por sobrevivência das pessoas que vivem no Pólo situa-se fora de sua residência, pois, mesmo aqueles que trabalham no onde moram possuem vínculo de trabalho em outro lugar, conclui-se então, que tal processo contribuiu para explicar a dinâmica sociodemográfica dos municípios.

A migração nos municípios do Pólo de Jeremoabo, a partir indicadores de deslocamento populacional foi representada pela evolução dos números referente as áreas de trabalho, sendo elas: agricultura, construção civil e comércio. (GRÁFICO 1)

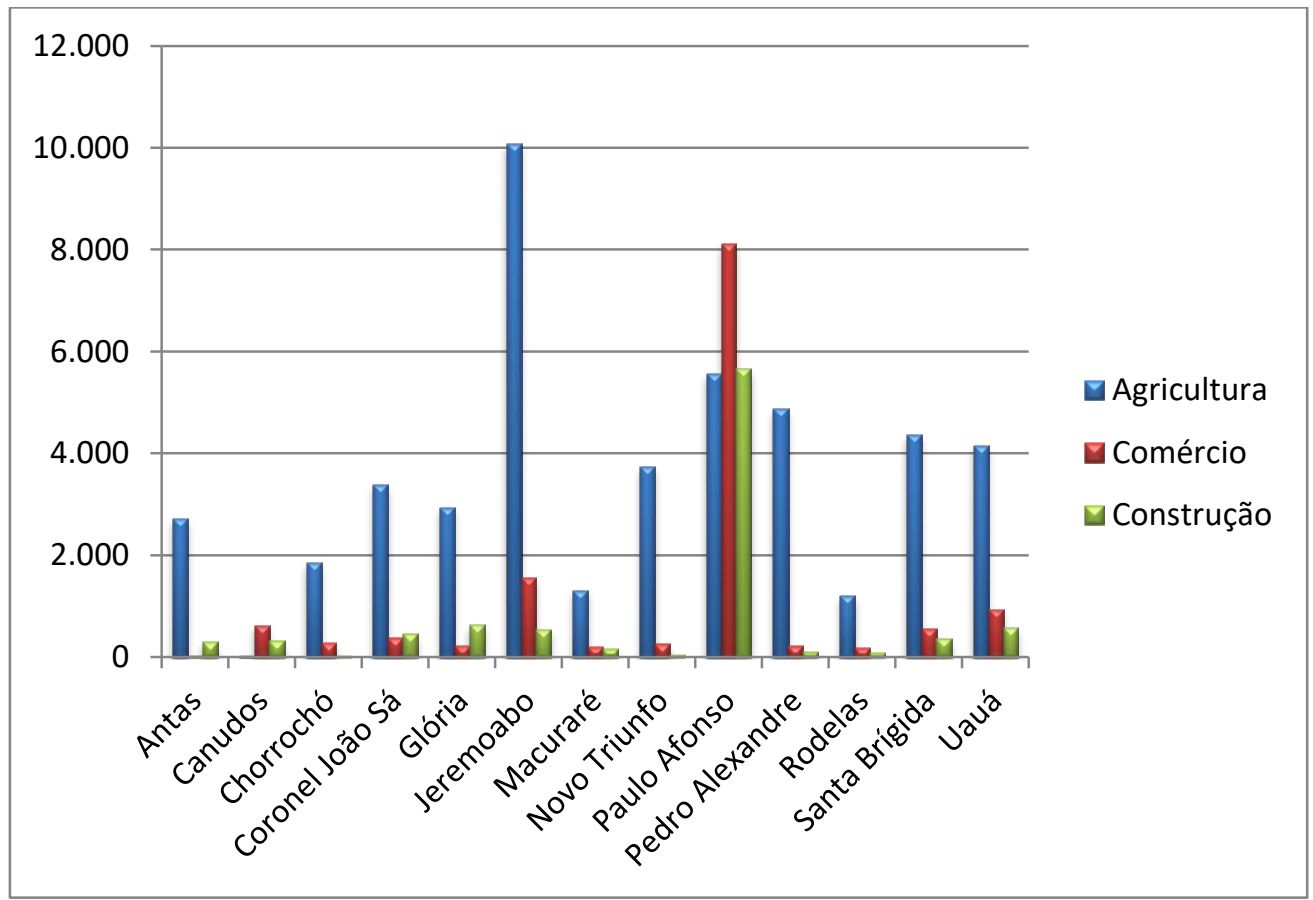

Gráfico 1: Pólo de Jeremoabo: evolução da migração por área de trabalho (2010).

Fonte: Censo Demográfico do Instituto Brasileiro de Geografia e Estatística (IBGE-2010)

A leitura dos números referentes à localização das áreas de trabalho identificou que a agricultura é o setor que possui índices de deslocamento com maior expressividade, especialmente para os municípios de Jeremoabo, Paulo Afonso, Pedro Alexandre, Santa Brígida e Uauá. No setor do comércio, somente os municípios de Jeremoabo, Santa Brígida e Uauá, são estes que apresentam pessoas que se deslocam para trabalhar, correspondendo a menos de 2.000 pessoas. O setor da construção civil também ocorre índice expressivo de migração, nota-se que Paulo Afonso apresentou os 
maiores índices de migração, enquanto os outros municípios expõem o deslocamento com números inferiores a 4.000 pessoas.

A análise dos dados permite explicar a importância da questão ambiental, relacionada ao desenvolvimento equilibrado do meio ambiente como também no que se refere à relação sociedade-natureza, e principalmente quanto ás relações de trabalho. $\mathrm{O}$ trabalho que envolve o uso e manejo dos recursos naturais teve deslocamento populacional com valores acima de 4.000 pessoas, especificamente para os municípios de Jeremoabo teve 10.086 pessoas, Paulo Afonso com 5.570 pessoas, Pedro Alexandre com 4.883, Santa Brígida teve 4.372 e Uauá pessoas, com 4.147 pessoas. Pode-se concluir que estes são os municípios que precisam de maior atenção quanto à questão da vulnerabilidade, devido o setor agrícola ser o maior responsável pelo deslocamento populacional.

\section{CONSIDERAÇÕES FINAIS}

A leitura dos dados sociodemográficos, demonstrou que ocorre no Pólo de Jeremoabo principalmente a migração temporária, especificamente nos setores da agricultura, construção civil, indústria, doméstico e atividades de serviço, enquanto a migração pendular observa-se o comércio, informalidade, construção civil, agrícola e indústria são as mais importantes. A desigualdade socioespacial é caracterizada pela venda da força de trabalho, especificamente quando as pessoas migram para exercer ocupação em mais de um município, registrando em Paulo Afonso como o que possui o maior número de pessoas migrando. Ao observar as áreas de migração para essas atividades econômicas, pode-se identificar a agricultura com índices de deslocamento com expressividade, especialmente para os municípios de Jeremoabo, Paulo Afonso, Pedro Alexandre, Santa Brígida e Uauá.

A vulnerabilidade socioambiental decorrente do processo de influencia no desenvolvimento da agricultura e consequentemente as pessoas que vivem do trabalho relacionado à produção agrícola, merecem atenção os municípios de Paulo Afonso, Pedro Alexandre, Santa Brígida e Uauá.

\section{REFERÊNCIAS}

GAUDEMAR, Jean Paul. de. Mobilidade do trabalho e acumulação do capital. Lisboa: Editorial Estampa, 1977.

LEWIS, Warren Hamilton. Economic Development With Unilimited Supplies of Labor. Manchester School of Economic and Social Studies, 1954. IN: "Migrações: o fato e a controvérsia teórica" In: VIII encontro Nacional de Estudos Populacionais. Anais, v. 3, São Paulo. ABEP, 1992, PP 119-144.

SALIM, Celso Amorim. Estrutura agrária e dinâmica migratória na região CentroOeste, 1970-80: análise do êxodo rural e da mobilidade da força de trabalho no contexto de industrialização da agricultura e da fronteira urbanizada. Tese de doutorado em Demografia, Cedeplar, UFMG, Belo Horizonte, 1992. 354p.

SINGER, Paul. Economia política da urbanização. São Paulo: Brasiliense, 1973. IN: SOARES, Weber. Análise de redes sociais e os fundamentos teóricos da migração internacional. Revista brasileira de Estudos Populacionais, Campinas, v. 21, n. 1, p. 101-116, jan./jun. 2004.

NETO, Helion Póvoa. Migrações Internas e Mobilidade do Trabalho no Brasil Atual: Novos Desafios Para Análise. Editora: Experimental. n.2, pg 11-24, março 1997 